\title{
Fabrication of DDS-3, an 11.4 GHz Damped-Detuned Structure
}

\author{
J. Klingmann, J. Elmer, M. Mugge, K. van Bibber \\ K. Asano, Y. Funahashi, Y. Higashi, T. Higo \\ N. Hitomi, T. Suzuki, T. Takatomi, N. Toge \\ Y. Watanabe, C. Adolphsen, H. Hoag, R. Jones \\ N. Kroll, R. Miller, C. Pearson, R. Pope \\ J. Rifkin, R. Ruth, J. Wang
}

This paper was prepared for submittal to the

Particle Accelerator Conference '99

New York, NY

March 29-April 2, 1999

March 1999

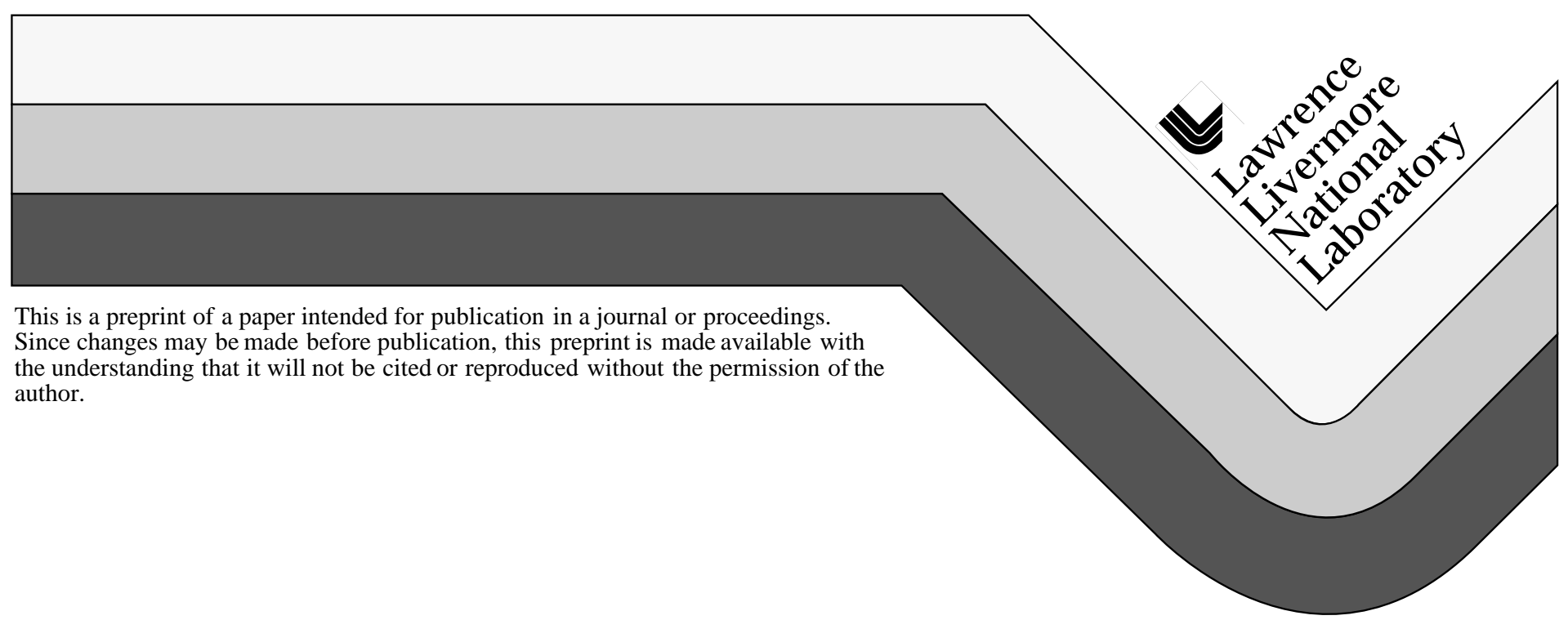




\section{DISCLAIMER}

This document was prepared as an account of work sponsored by an agency of the United States Government. Neither the United States Government nor the University of California nor any of their employees, makes any warranty, express or implied, or assumes any legal liability or responsibility for the accuracy, completeness, or usefulness of any information, apparatus, product, or process

disclosed, or represents that its use would not infringe privately owned rights. Reference herein to any specific commercial product, process, or service by trade name, trademark, manufacturer, or otherwise, does not necessarily constitute or imply its endorsement, recommendation, or favoring by the United States Government or the University of California. The views and opinions of authors expressed herein do not necessarily state or reflect those of the United States Government or the University of California, and shall not be used for advertising or product endorsement purposes. 


\section{FABRICATION OF DDS-3, AN 11.4 GHz DAMPED-DETUNED STRUCTURE}

J. Klingmann, J. Elmer, M. Mugge, K. van Bibber, LLNL, Livermore, CA 94550 USA

K. Asano, Y. Funahashi, Y. Higashi, T. Higo, N. Hitomi, T. Suzuki, T. Takatomi, N. Toge, Y.

Watanabe, KEK, Tsukuba, Ibaraki 305, Japan

C. Adolphsen, H. Hoag, R. Jones, N. Kroll, R. Miller, C. Pearson, R. Pope, J. Rifkin, R. Ruth, J.

Wang, SLAC, Stanford, CA 94309 USA

\section{Abstract}

A 1.8 m X-band Damped-Detuned Structure (DDS-3) has been fabricated and characterized as part of the structure development program towards a $\mathrm{TeV}$-scale $\mathrm{e}^{+} \mathrm{e}^{-}$linear collider. In this joint venture, the copper cells were precision-fabricated by LLNL, diffusionbonded into a monolithic structure by KEK, and the structure completed and tested by SLAC. The overall process constitutes a baseline for future high-volume structure manufacture.

\section{INTRODUCTION}

The US-Japan technical baseline for a TeV-scale $\mathrm{e}^{+} \mathrm{e}^{-}$ linear collider builds upon a $1.8 \mathrm{~m}$ long $\mathrm{X}$-band accelerator structure for the main linacs. These structures are of the Damped-Detuned type, whereby the cell dimensions are varied continuously along the length in such a way to maintain a uniform $2 \pi / 3$ phase advance in the accelerating mode at $11.424 \mathrm{GHz}$, but distribute the first dipole mode frequencies according to a broad, smooth function centered around $15 \mathrm{GHz}$. Furthermore, the dipole modes excited by off-axis bunches are effectively coupled out to damping manifolds, where their energy propagates to terminations at either end. In this way, the long-range dipole wakefields may be suppressed. The basic DDS concepts are discussed in [1], and an overall summary of the R\&D on Detuned and Damped-Detuned Structures is found in [2]. This paper will focus mainly on the production of the 206 different copper cells. The stacking and two-step bonding of these cells into the DDS-3 structure is described in detail in [3]. The actual wakefields of DDS-3 as measured in the SLAC ASSET facility is reported in [4]. A cross section of the DDS-3 structure is shown in Figure 1.

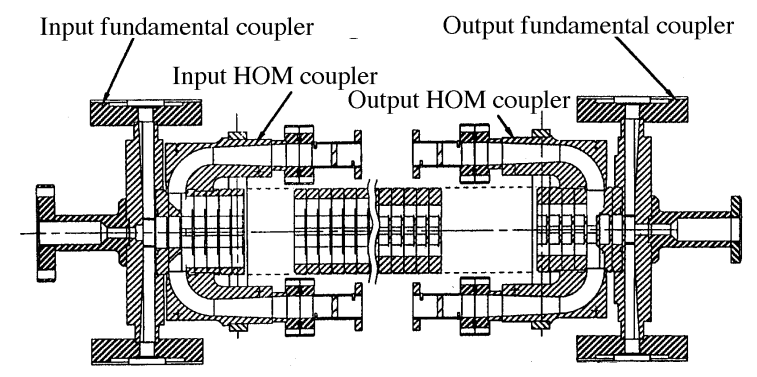

Figure 1: Cross section of the DDS 3 structure.

*Now at Akita National College of Technology.

\section{CELL FABRICATION}

A schematic of the DDS-3 cell is shown with an isometric rendering in Figure 2. Five dimensions are specified on the drawing, 'A', 'B', ' $t$ ', 'H', and ' $L$ ', which vary over the length of the structure. Table 1 shows the dimensions of three cells along the structure to indicate the magnitudes of the variations. All dimensions are specified at $20{ }^{\circ} \mathrm{C}$.
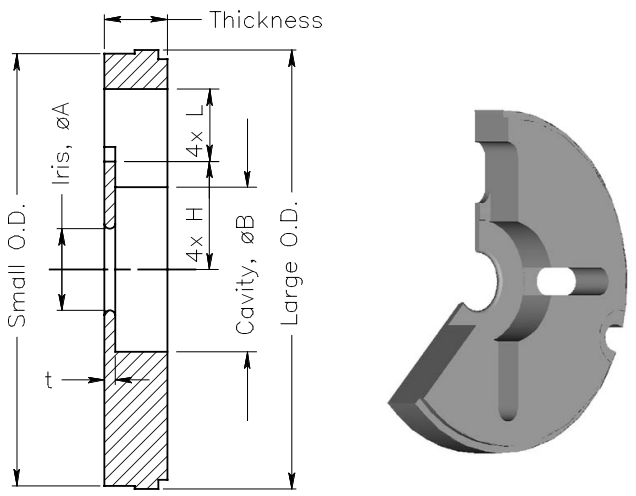

Figure 2: Cross-section and rendering of the DDS-3 cell.

\subsection{Tolerance Requirements}

The axisymmetric features of the DDS-3 cells have tolerances in the 0.5 to 1.0 micrometer range and surface finish requirements of less than $500 \AA \mathrm{R}_{\mathrm{a}}$. The primary and secondary datums of the design are the flat face on the non-cavity side of the cell and the outside diameter of the cell, respectively. Two relationships are critical to maintain for proper performance. The first is parallelism of the two bonding surfaces to 0.5 micrometer over the diamete $r$ to prevent a variable "walk" in the straightness of the structure. The second is 1 micrometer concentricity of the cavity and iris to the outside diameter, the radial reference during assembly. The HOM port dimensions have tolerances in size and position in the 20micrometer range.

Table 1: DDS -3 Cell Parameters

\begin{tabular}{|l|c|c|c|c|c|}
\hline $\begin{array}{l}\text { Cell } \\
\text { No. }\end{array}$ & $\begin{array}{c}\text { A } \\
(\mathbf{m m})\end{array}$ & $\begin{array}{c}\text { B } \\
(\mathbf{m m})\end{array}$ & $\begin{array}{c}\mathbf{t} \\
(\mathbf{m m})\end{array}$ & $\begin{array}{c}\mathbf{H} \\
(\mathbf{m m})\end{array}$ & $\begin{array}{c}\mathbf{L} \\
(\mathbf{m m})\end{array}$ \\
\hline
\end{tabular}




\begin{tabular}{|r|r|r|r|r|r|}
\hline 3 & 11.175 & 22.311 & 1.056 & 11.053 & 14.668 \\
\hline 103 & 9.593 & 21.527 & 1.459 & 10.514 & 11.997 \\
\hline 201 & 8.186 & 20.853 & 1.876 & 10.300 & 8.804 \\
\hline
\end{tabular}

\subsection{Fabrication Procedure}

Disks were first saw-cut from annealed high-purity copper (UNS C10100) barstock, and the axisymmetric features turned to leave overstock material of 20 to 25 micrometers. The slot features that constitute the higher order mode (HOM) manifolds were then milled out to their final finished surface. At this point, the part was annealed in $10^{-6}$ Torr vacuum at $500{ }^{\circ} \mathrm{C}$ for one hour, to remove residual compressive stresses left in the surface from the roughing operations. This was necessary to prevent shape changes as material is removed during finishing.

The finishing operation was completed on a Precitech T-base diamond-turning lathe. This lathe has an air-bearing spindle, oil hydrostatic slideway bearings, and Zerodur glass scales with resolution of 8.4 nanometers. Of course, machine accuracy is significantly poorer, largely due to thermal errors. Single crystal diamond tools with a 0.25 -millimeter radius and the rake set to 0 degrees were used for finishing. The usual procedure was to finish the noncavity side of the part first, holding the part with a collet on the larger outside diameter (see Figure 2). This step resulted in precision finished surfaces on the smaller outside diameter, one flat surface, and half of the iris. In the second step, the part was fixtured with a vacuum chuck on the side turned flat in the first operation and with a close-fitting ( 0 to 0.5 micrometers clearance) ring around the smaller outside diameter. The vacuum chuck, collet, and a part are shown in Figure 3.

This method can yield very accurate parts because it allows the datum (larger outside diameter), cavity, and half of the iris to be cut in a single setup. Nonconcentricities of these features should only result from the machine spindle errors which are quite small. The only feature that could be significantly non-concentric is the half of the iris that is cut during the first operation. Additionally, because the second set of axial surfaces is cut when the part is located on a machinedin-place vacuum chuck, parallelism should also be very good. About half the parts were finished with only two setups; the other half required successive operations.

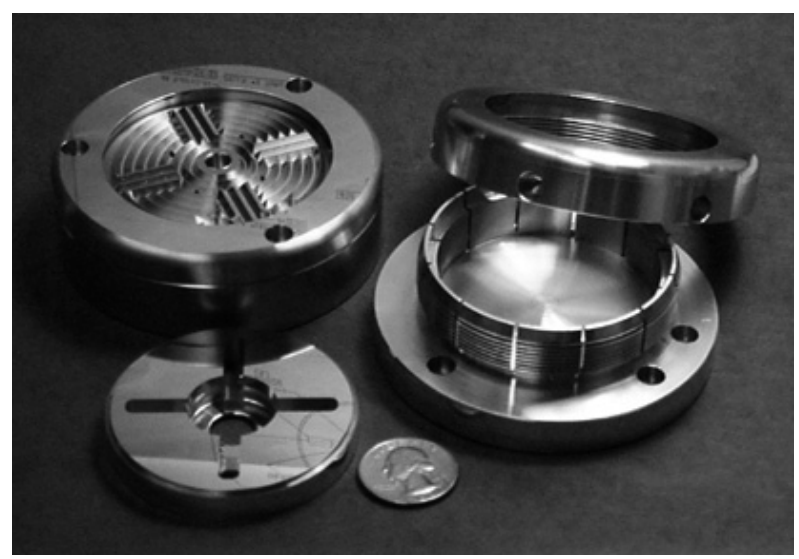

Figure 3: DDS-3 cell with diamond-turning fixtures.

Quality control was challenging due to the very small tolerances. Our strategy was to derive most of our accuracy from the metrology loop on the turning machine. For axial dimensions, the vacuum chuck was cut as a reference surface and, with intimate contact between this surface and the part, faces could be cut accurately. The vacuum chuck was designed to minimize contact area and thus particulate contaminants were not likely to compromise cell axial location. For diameters, a part that could be measured accurately was first cut. The difference between the measured and programmed diameters on this part contained thermal expansion and tool-spindle relationship errors. The machine that turned the DDS-3 parts did not have good temperature control and the temperature of the part had to be estimated to correct for the thermal error. After applying this correction, the remaining error in the test part was due to the tool not being registered to the spindle centerline. This error causes inside and outside diameter size errors that are equal in magnitude but opposite in sign. By contrast, thermal errors are proportional to the radius of the feature and are of the same sign. These references, the axial face cut and a test part diameter, must be set each time that a new tool is installed on the machine. With the precision machine metrology found on diamond-turning lathes, this strategy can result in more accurate dimensions throughout the part than can be measured by other means.

\subsection{Metrology}

Sufficiently accurate metrology was one of the major shortcomings in cell fabrication. The only features that could be measured to the accuracy of the specifications on the drawing were the cell flatness and outside diameters. Being a fast and inexpensive procedure, flatness was measured frequently with a Zygo Mark IV interferometer. Typical cell interferograms are shown in Figure 4; most cells were flat to less than 0.4 micrometers over the bonding surface. A 'bookshelving' error, where the individual 
cell axes are not parallel with the structure axis, was noted during post-assembly tests. It is unlikely that nonparallelism in the cells would yield the character of the error seen in the data. Furthermore, the parallelism for each cell was measured at KEK prior to assembly and all were less than 2 micrometers parallel (across the diameter) with the average value and standard deviation being 0.45 -and 0.44 -micrometers, respectively.

The only dimension that was measured in a somewhat in-process manner was the outside diameter, which was also the setup diameter for the quality control on the machine. LLNL has the capability to measure outside diameters in this size range with accuracy to 0.125-micrometers, NIST-traceable. At that level of accuracy however, the measurement is not fast enough to be very useful in an in-process sense. Thus only a limited number were measured, these data shown in Figure 5. The outside diameters of more parts were checked with a comparison gauge that compares the diameter to an artifact part; repeatability of this instrument was in the 0.125 -micrometer range.

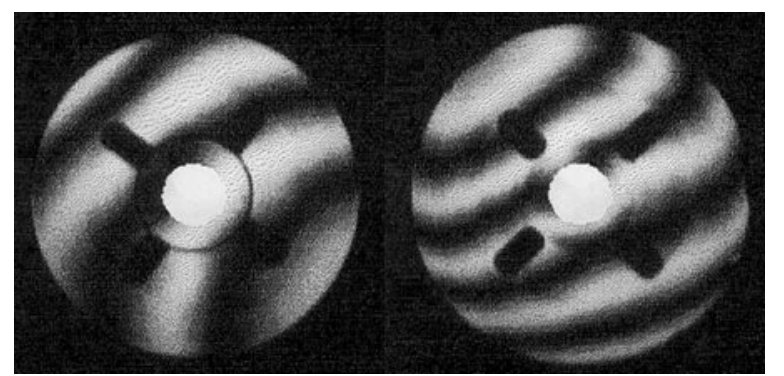

Figure 4: Interferogram showing better than 0.3micrometer flatness on each side of cell \#178.

Independently verifying the other critical axisymmetric cell features to a higher precision than can be made on the diamond-turning lathe is difficult; we relied heavily on the quality control process described in the previous section. For large-volume production, the emphasis will be on microwave qualification, both single-cell and full-structure, more closely related to actual performance. Functional tests that were performed included single-cell and bead-perturbation microwave tests and the ASSET wakefield characterization $[2,4]$.

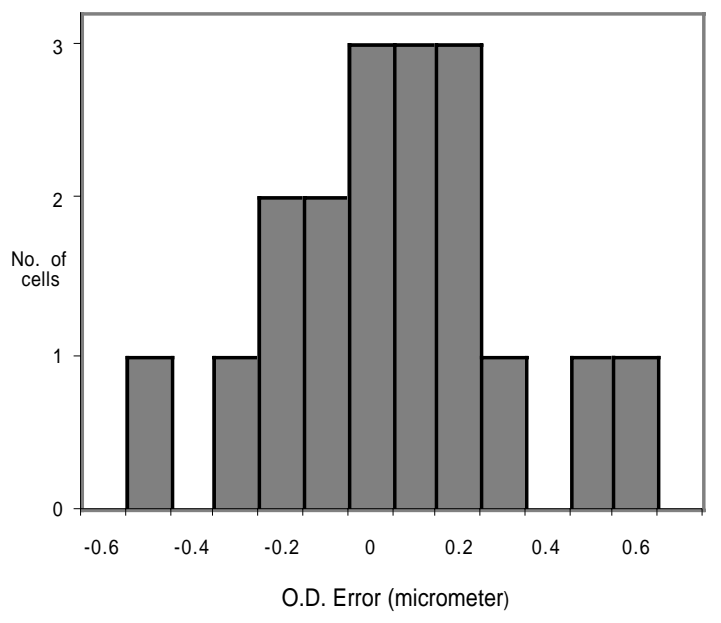

Figure 5: Cell O.D. error distribution.

\section{CONCLUSIONS \& FUTURE WORK}

The purpose of this prototype was to gain practical experience in building structures to guide the manufacturing strategy. Future structures will incorporate a new electromagnetic design, the Round Damped-Detuned Structure (RDDS) [5,6], that will significantly improve machine efficiency. However, lessons learned in DDS-3 will carry over completely to the new design.

Our initial assumption had been that the production of a structure was a precision engineering problem, requiring machines that could fabricate cells with absolute accuracy in all dimensions. While ultimately successful, the difficulty of this task was greatly underestimated. Two important conclusions resulted from this project. First, large-volume structure manufacturing can not require machining with high absolute (sub-micrometer) accuracy. On the other hand, we are optimistic that the right strategy will be to require only that the machining is highly reproducible and the error in absolute dimensions will be driven to zero by feedback from accurate functional metrology in the production line. Second, the tolerances for DDS-3 were specified as 'top-hat' distributions, but it is now thought that this is overly restrictive. As structures are ensembles of a large number of cells, tolerances could be specified in terms of a mean error within a well-behaved error distribution. This should result in a much more relaxed machining procedure; in fact it may be essential for mass production. How this would actually be implemented has not yet been considered in detail.

One further outcome from this work has been to examine the possibility of making the cells with interlocking features (see Fig. 6). Such a design should be much more amenable to robotic assembly, as well as eliminate 'bookshelving' of cells within the 
structure. Tooling and cells are being fabricated for a test of this idea in a sub-section prototype.

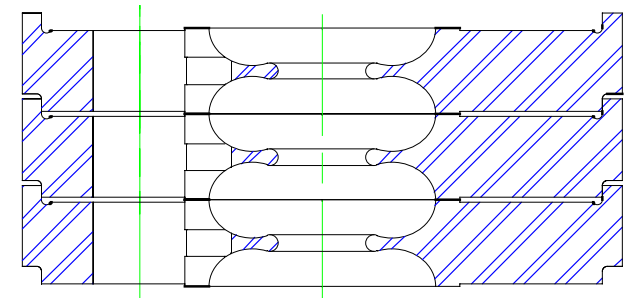

Figure 6: An interlocking cell with RDDS cavities.

\section{ACKNOWLEDGEMENTS}

We would like to acknowledge the contributions of our colleagues at the Oak Ridge National Laboratory, Joe Cunningham and Art Miller, and at LLNL, Anthony Demiris, Blaine Beith, Don Bennett, and Larry Wagner.

This work was supported in part by the Japan-U.S. Collaboration Program in High Energy Physics Research, and the U.S. Department of Energy under Contract Nos. DE-AC03-76SF00515 (SLAC), and W7405-ENG-48 (LLNL).

\section{REFERENCES}

[1] N. Kroll, Proc. PAC'97, SLAC-PUB-7541.

[2] J.W. Wang et al., paper FRA18, PAC'99.

[3] T. Higo et al., paper FRA16, PAC'99.

[4] C. Adolphsen et al., paper FRA40, PAC'99.

[5] R.M. Jones et al., paper FRA37, PAC'99

[6] Z. Li et al., paper FRA41, PAC'99 